\title{
Wolinella succinogenes
}

National Cancer Institute

\section{Source}

National Cancer Institute. Wolinella succinogenes. NCI Thesaurus. Code C86851.

A species of anaerobic, Gram negative, rod shaped bacteria assigned to the phylum

Proteobacteria. This species is motile, oxidase positive, peroxidase and urease negative and cannot metabolize carbohydrates. W. succinogenes is a commensal organism of the gastrointestinal tract and may be an emerging pathogen. 